\title{
Cytopathologic Features of Secretory Carcinoma of Salivary Gland: Report of Two Cases
}

Young Ah Kim · Jae Won Joung Sun-Jae Lee · Hoon-Kyu Oh

Chang Ho Cho . Woo Jung Sung

Department of Pathology, Catholic University of Daegu School of Medicine, Daegu, Korea

Received: October 31, 2018

Revised: November 8, 2018

Accepted: November 9, 2018

\section{Corresponding Author}

Woo Jung Sung, MD, PhD

Department of Pathology, Catholic University of

Daegu School of Medicine, 33 Duryugongwon-ro

17-gil, Nam-gu, Daegu 42472, Korea

Tel: +82-53-650-4159

Fax: +82-53-650-3456

E-mail: wjsung@cu.ac.kr
Secretory carcinoma of the salivary gland (SC) is a newly introduced rare salivary gland tumor that shares histological, immunohistochemical, and genetic characteristics with secretory carcinoma of the breast. Here, we report the cytologic features of two cases of SC confirmed by surgical resection. In these two cases, SC was incidentally detected in a 64-year-old female and a 56-yearold male. Fine needle aspiration cytology revealed nests of tumor cells with a papillary or glandular structure floating in mucinous secretions. The tumor cells demonstrated uniform, round, smooth nuclear contours and distinct nucleoli. Multiple characteristic cytoplasmic vacuoles were revealed. Singly scattered tumor cells frequently showed variable sized cytoplasmic vacuoles. The cytopathologic diagnosis of SC should be considered when characteristic cytological findings are revealed. Further immunohistochemistry and gene analyses are helpful to diagnose SC.

Key Words: Secretory carcinoma; Mammary analogue secretory carcinoma; Salivary gland; Cytology
Secretory carcinoma of salivary gland (SC) is a distinctive low-grade tumor recently described in the 2017 WHO classification of head and neck tumors. SC shares histological, immunohistochemical, and genetic features with secretory carcinoma of the breast. ${ }^{1}$ Histologically, secretory carcinomas of both the salivary gland and breast are composed of uniform cells with characteristic eosinophilic granular or vacuolated cytoplasm arranged in microcystic, solid, tubular, and follicular growth patterns. Akin to that in a secretory breast cancer, SC expresses S100 protein, mammaglobin, and vimentin, and has a $\mathrm{t}(12 ; 15)$ (p13;q25) translocation, which leads to the formation of the ETV6-NTRK3 fusion product. ${ }^{2}$

SC is usually a painless, slow-growing mass that ranges in size from 1 to $4 \mathrm{~cm}^{3}$ SC usually involves the parotid gland (about 70\%), ${ }^{4}$ followed by the submandibular gland (about $7 \%$ ). It rarely affects other sites, including the minor salivary glands of the oral cavity. ${ }^{5}$ The mean age of SC patients is $46 .{ }^{5}$ years (age range, 10 to 86 years). ${ }^{6}$ SC shows indolent behavior, but local recurrence was reported in $25 \%$ of cases, lymph node metastasis was reported in $20 \%$ of cases, and metastasis was reported in $5 \%$ of cases. ${ }^{6,7}$ The rate of lymph node metastasis was slightly greater than that of ACC. ${ }^{8,9} \mathrm{SC}$ with high-grade transformation has been described in the literature. ${ }^{10-12}$

Fine needle aspiration (FNA) cytology is a widely used efficient first line diagnostic tool for salivary gland lesions. The reports of cytologic findings of SC are limited and describe a wide range of cytomorphologic characteristics. In this study, we report the cytopathologic findings of two cases of SC confirmed in surgical specimens by histological and genetic analysis.

This study was approved by the Institutional Review Board of Catholic University of Daegu Medical Center (IRB No. CR18-155), and informed consent was waived.

\section{CASE REPORT}

\section{Case 1}

A 64-year-old female without any medical history incidentally found an asymptomatic mass on her left mandible angle. On physical examination, an approximately $0.5 \times 0.5$-cm-sized movable firm mass was detected. Ultrasonography revealed an approximately $1.0 \times 0.7-\mathrm{cm}$-sized hypoechoic mass at the anterior portion of the parotid gland. 
FNA cytology revealed a cellular aspirate composed of papillary nests or follicular architecture with individually dispersed cells (Fig. 1A). The background showed abundant mucinous material with a small population of scattered lymphocytes (Fig. 1B). The tumor cells showed large, relatively uniform round nuclei with smooth nuclear contours, fine chromatin, and distinct eosinophilic nucleoli (Fig. 1C). The cytoplasm of individual tumor cells was granular, pale, or vacuolated. Cytoplasmic vacuoles showed variable sizes and were usually small, although some cells showed macrovacuoles reminiscent of signet ring cells (Fig. 1D, E). Individual cells with binucleated and eccentric nuclei were easily identified (Fig. 1F). FNA cytology was diagnosed as acinic cell carcinoma (ACC).

After FNA, left parotidectomy was performed. On gross exami- nation of the surgical specimen, a well-demarcated tan to yellowish mass was identified. Microscopically, a well-encapsulated mass with a focally infiltrative margin was noted. The tumor was composed of microcystic, follicular, and focal papillary architecture with homogeneous eosinophilic colloid-like luminal secretions (Fig. 1G). The tumor cells had granular or vacuolated cytoplasm, and vacuolated tumor cells were frequently identified at the papillary growing area. There was no necrosis, mitotic figures, lymphovascular invasion, or neural invasion. Immunohistochemical stains showed diffuse strong positive reactivity for S100 protein (Fig. 1H), mammaglobin, gross cystic disease fluid protein 15 (GCDFP-15), cytokeratin 7 (CK7), epithelial membrane antigen (EMA), and focal weak positive reactivity for DOG1. No reactivity was noted for smooth muscle actin (SMA) and
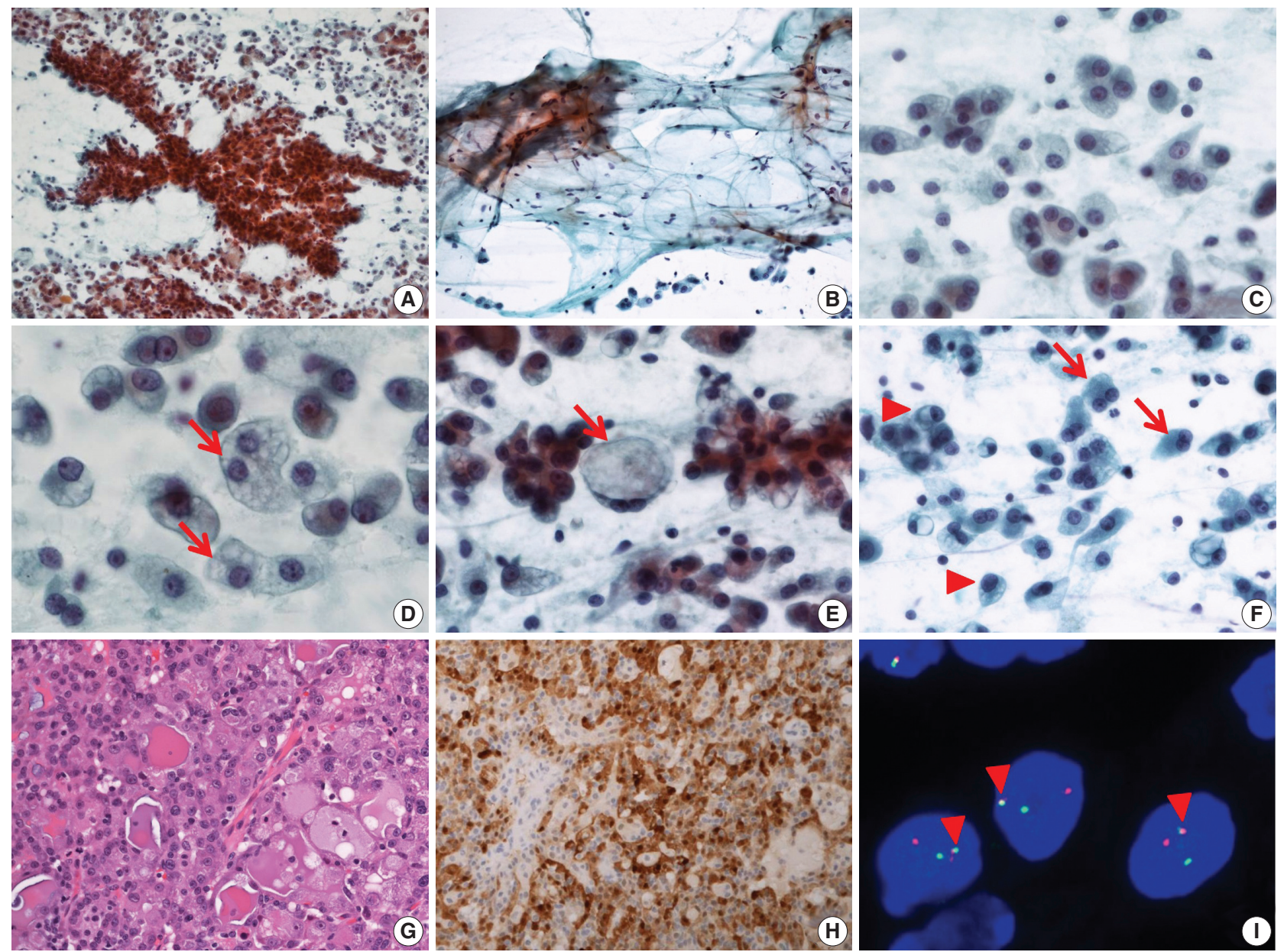

Fig. 1. Cytopathologic features of case 1. (A) The specimen has high cellularity and nest with papillary structure. (B) Mucinous background is easily recognized with scattered lymphocytes and individual tumor cells. (C) Tumor cells have uniform, round nuclei and distinct nucleoli. (D) Various sized cytoplasmic vacuoles (arrows) are noted. (E) Some macrovacuoles (arrow), similar to signet ring cells, may be seen. (F) Some tumor cells show binucleation (arrows) or eccentric nuclei (arrowheads). (G) The tumors consist of microcystic or follicular structures with eosinophilic secretions. (H) Strong diffuse immunoreactivity to S100 protein. (I) ETV6 fluorescence in situ hybridization showing one fused (arrowheads) and one split (red and green) signal indicative of ETV6 translocation. 
p63. ETV6 gene translocation was confirmed by fluorescence in situ hybridization (FISH) using a dual-color break-apart ETV6 probe (Abbott Molecular, Des Plaines, IL, USA) (Fig. 1I). The patient showed no evidence of recurrence or metastasis at 1-yearfollow up.

\section{Case 2}

A 56-year-old male without any past history found an asymptomatic mass on the left parotid area. On physical examination, an approximately $2.5 \times 2.0-\mathrm{cm}$-sized hard movable mass was detected. Ultrasonography revealed a $2.6 \times 1.8$-cm-sized well demarcated isoechoic mass in the left parotid gland.

On FNA cytology, cellularity was relatively low (Fig. 2A). The aspirate material consisted of cohesive epithelial cells and loose trabecular nests with hemosiderin-laden macrophages
(Fig. 2B). Tumor cell nuclei had minimal anisonucleosis and were centrally located (Fig. 2C). The tumor cells showed a moderate amount of eosinophilic fine granular or clear cytoplasm (Fig. 2D). Vacuolated cells were relatively rare (Fig. 2E, F). The aspirate was diagnosed as benign because it had low cellularity and the vacuolated cells were recognized as macrophages.

The patient underwent a partial left parotidectomy. On gross examination, a well-circumscribed cystic mass with an intracystic solid portion was identified, measuring $2.5 \times 1.8 \mathrm{~cm}$ in dimension. Microscopically, the tumor was lobulated by fibrous septa and exhibited cyst formation. The centrally located solid area was composed of microcystic and follicular architecture (Fig. $2 \mathrm{G})$. The tumor cells showed eosinophilic granular and occasionally vacuolated cytoplasm. On immunohistochemistry, the tumor cells were reactive for S100 protein, mammaglobin (Fig.
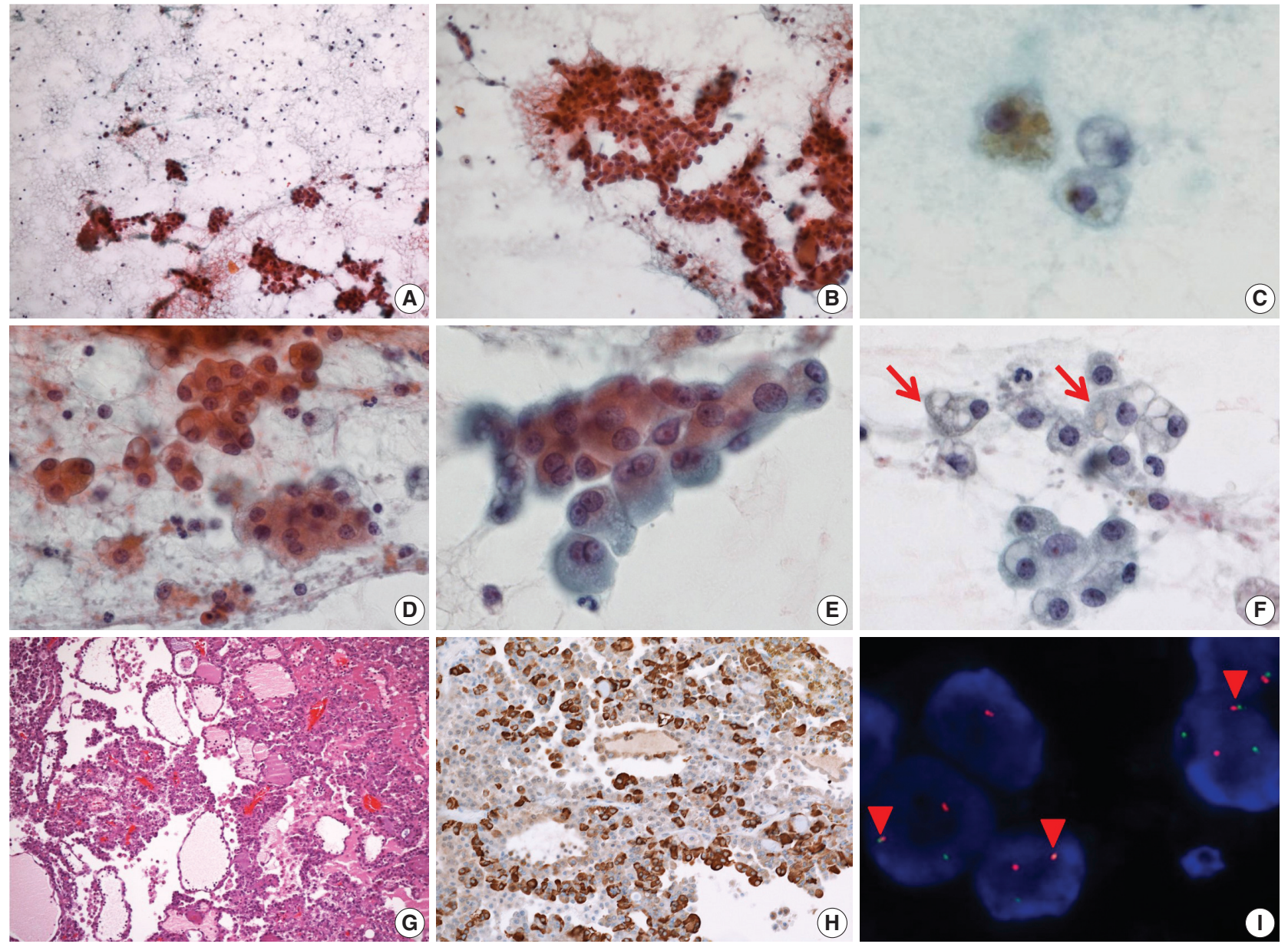

Fig. 2. Cytopathologic features of case 2. (A) The specimen has low cellularity compared with case 1. (B) Loose trabecular nests of tumor cells are noted. (C) Hemosiderin laden macrophages are found. (D) Tumor cells have uniform, centrally located nuclei. (E) Tumor cells show eosinophilic and fine granular cytoplasm. (F) Sometimes, vacuolated cells (arrows) are encountered. (G) Tumor cells show microcystic, follicular architecture with eosinophilic secretions. (H) Strong immunoreactivity to mammaglobin is noted. (I) ETV6 fluorescence in situ hybridization showing one fused (arrowheads) and one split (red and green) signal indicative of ETV6 translocation. 
2H), CK7, and EMA, and no reactivity was noted for GCDFP-15, SMA, and p63. As in case 1, weak and focal positive immunoreaction for DOG1 stain was identified. Fusion of ETV6 and NTRK gene was revealed by FISH (Fig. 2I). At first, the mass was diagnosed as papillary cystic variant ACC. In the retrospective review of previous cases of SC, the present case was confirmed as SC. No local recurrence or distant metastasis has been noted in the patient for the past 9 years.

\section{DISCUSSION}

The cytologic findings on FNA of SC have been reported as cellular smears composed of cohesive cell groups of papillary, solid, or discohesive architecture. Tumor cells have round nuclei with vacuolated or granular cytoplasm. The most easily recognized cytologic finding of SC is cells with cytoplasmic vacuoles. However, vacuolated tumor cells can be found in ACC or in mucoepidermoid carcinoma (MEC) as well as in SC. The tumor cells of classic ACC have a variable amount of cytoplasmic zymogen granules, which are periodic acid-Schiff-positive and diastase resistant. Zymogen granule poor ACC shows considerable morphologic overlap with SC. ${ }^{2}$ However, ACC demonstrates cytologic and structural diversity, whereas SC is structurally homogeneous and uniformly composed of microcystic and glandular spaces with luminal secretory material. ${ }^{1}$ The tumor cells of SC exhibit small nuclei and smooth nuclear membrane contours on FNA compared to cells of ACC. SC frequently shows vacuolated cytoplasm and a singly scattered pattern. MEC is also a major differential diagnosis. FNA of MEC seldom shows isolated cells, whereas SC usually presents with abundant isolated single cells. ${ }^{12}$

We initially reported the FNA of case 2 as a benign lesion because vacuolated tumor cells were recognized as macrophages with cystic change. However, in a retrospective review, the nuclei of the vacuolated tumor cells were relatively uniform in size with smooth nuclear contours. The tumor cells formed small clusters, whereas macrophages tend to be singly dispersed. FNA specimens of low-grade tumors with cystic change usually have low cellularity, and macrophages are frequently identified. Therefore, it is difficult to distinguish vacuolated tumor cells from macrophages.

In summary, the cytologic characteristics of SC included papillary or other cellular nests and individual tumor cells with abundant and granular to vacuolated cytoplasm. The tumor cells showed uniform and round nuclei with distinct nucleoli. The background mucinous material is helpful for diagnosis. However, the cytologic features overlap with those of other salivary gland neoplasms, such as ACC and MEC, and benign cystic lesions. A definite diagnosis of SC by FNA is difficult, but cytopathologists should suggest the possibility of SC when presented with characteristic cytologic findings on FNA. Immunohistochemistry and verification of ETV6-NTRK3 fusion gene are useful to differentiate SC from other salivary gland tumors.

\section{ORCID}

Young Ah Kim: https://orcid.org/0000-0001-7850-5509

Jae Won Joung: https://orcid.org/0000-0001-9466-3240

Sun-Jae Lee: https://orcid.org/0000-0002-8552-6049

Hoon-Kyu Oh: https://orcid.org/0000-0001-8793-1948

Chang Ho Cho: https://orcid.org/0000-0003-2708-6011

Woo Jung Sung: https://orcid.org/0000-0001-9510-3763

\section{Conflicts of Interest}

The authors declare that they have no potential conflicts of interest.

\section{REFERENCES}

1. Skalova A, Vanecek T, Sima R, et al. Mammary analogue secretory carcinoma of salivary glands, containing the ETV6-NTRK3 fusion gene: a hitherto undescribed salivary gland tumor entity. Am J Surg Pathol 2010; 34: 599-608.

2. Skalova A. Mammary analogue secretory carcinoma of salivary gland origin: an update and expanded morphologic and immunohistochemical spectrum of recently described entity. Head Neck Pathol 2013; 7 Suppl 1: S30-6.

3. Parekh V, Stevens TM. Mammary analogue secretory carcinoma. Arch Pathol Lab Med 2016; 140: 997-1001.

4. Boon E, Valstar MH, van der Graaf WT, et al. Clinicopathological characteristics and outcome of 31 patients with ETV6-NTRK3 fusion gene confirmed (mammary analogue) secretory carcinoma of salivary glands. Oral Oncol 2018; 82: 29-33.

5. Sethi R, Kozin E, Remenschneider A, et al. Mammary analogue secretory carcinoma: update on a new diagnosis of salivary gland malignancy. Laryngoscope 2014; 124: 188-95.

6. El-Naggar AK, Chan JK, Grandis JR, Takata T, Slootweg PJ. WHO classification of head and neck tumours. Lyon: International Agency for Research on Cancer, 2017.

7. Bishop JA, Yonescu R, Batista DA, Westra WH, Ali SZ. Cytopathologic features of mammary analogue secretory carcinoma. Cancer Cytopathol 2013; 121: 228-33.

8. Seethala RR, Stenman G. Update from the 4th edition of the World 
Health Organization classification of head and neck tumours: tumors of the salivary gland. Head Neck Pathol 2017; 11: 55-67.

9. Chiosea SI, Griffith C, Assaad A, Seethala RR. Clinicopathological characterization of mammary analogue secretory carcinoma of salivary glands. Histopathology 2012; 61: 387-94.

10. Skálová A, Vanecek T, Majewska H, et al. Mammary analogue secretory carcinoma of salivary glands with high-grade transformation: report of 3 cases with the ETV6-NTRK3 gene fusion and analysis of TP53, beta-catenin, EGFR, and CCND1 genes. Am J
Surg Pathol 2014; 38: 23-33.

11. Luo W, Lindley SW, Lindley PH, Krempl GA, Seethala RR, Fung KM. Mammary analog secretory carcinoma of salivary gland with high-grade histology arising in hard palate, report of a case and review of literature. Int J Clin Exp Pathol 2014; 7: 9008-22.

12. Jung MJ, Kim SY, Nam SY, et al. Aspiration cytology of mammary analogue secretory carcinoma of the salivary gland. Diagn Cytopathol 2015; 43: 287-93. 